International Journal of Engineering \& Technology, $7(3.2)(2018) 236-238$
International Journal of Engineering \& Technology
SPC
Website: www.sciencepubco.com/index.php/IJET
Research paper

\title{
Experimental Investigations of the Stress and Strain State of Continuous Reinforced Concrete Beams Under the Action of Low-Cyclic Repetitive and Alternating Loads
}

\author{
Grigoriy Masiuk $^{1 *}$, Oleksandr Yushchuk ${ }^{2}$, Andrii Paschenko ${ }^{3}$ \\ ${ }^{I}$ National University Of Water And Environmental Engineering, Ukraine \\ ${ }^{2}$ National University Of Water And Environmental Engineering, Ukraine \\ ${ }^{3}$ Poltava National Technical Yuri Kondratyuk University, Ukraine \\ *Corresponding Author E-Mail: G.H.Masyuk@Nuwm.Edu.Ua
}

\begin{abstract}
The article is devoted to the experimental studies of the stress and strain state of the two-pass reinforced concrete beams under the influence of low-cyclic repeated and alternating loads. Based on the results of experimental studies, the effect of low-cyclic repeated and alternating loads on the change of the stress and strain state of continuous reinforced concrete beams has been established. In the course of testing the sample, it was found that the stress and strain state of the beams under the action of the above mentioned loads is significantly different from the stress and strain state of the beams under the action of nonalternating static loads, namely, the decrease of the bearing capacity, the increase of the deflections and the width of the cracking. All this is due to the change in the physical and mechanical properties of concrete in response to the above-mentioned loads on experimental.
\end{abstract}

Keywords: reinforced concrete two-pass beams, low-cyclic repetitive and alternating loads, stress and strain state.

\section{Introduction}

The use of reinforced concrete continuous beams during the erection of buildings and structures is widespread. Such structures are used in monolithic slabs of multi-storey public and industrial buildings, underground storage tanks, parking lots for cars, etc. In the course of their operation, continuous beams of slabs for the above mentioned buildings, low-cyclic repeated and alternating loads of different levels are tested, but their stress and strain state and its change are not sufficiently studied. It should be noted that the existing national $[1,2]$ and foreign $[3,4]$ methods of calculating continuous beams do not take into account the actions of the above-mentioned loads and their influence on the parameters of the stress and strain state.

\section{Problem Statement and Significance}

The investigation of the stress and strain state, which corresponds to the real operation of structures, is one of the main tasks for the development of the theory of their calculations. Low-cyclic alternating changes cause specific conditions for the operation of reinforced concrete structures and stipulate the changes in the mechanical and deformative characteristics of concrete, affect the fracture resistance and deformability of these elements.

A fairly large number of scientists have investigated the work of non-permeable reinforced concrete beams under unambiguous static loads. It has been lately discussed in works [5 ... 12]. As for the experimental and theoretical studies of the parameters of the stress-strain state of the continuous reinforced concrete beams, under the action of low-cyclic repetitive the research data are pub- lished in papers [13 ... 17]. However, the research of the stress and strain state and the operation of continuous reinforced concrete beams as a whole under the action of low-cyclic alternating loads has not been yet conducted. Therefore, given the above, this problem is becoming increasingly relevant.

Your paper must be in two column format with a space of $0.5 \mathrm{~cm}$ between columns.

\section{The Purpose and Tasks of the Research}

On the basis of experimental studies, to analyze the effect of lowcyclic repeated and alternating loads on the parameters of the stress-strain state of continuous reinforced concrete beams.

\section{Main Body}

To achieve the purpose, the experimental studies were carried out on the stress-strain state of two-pass continuous beams under the action of low-cyclic repeated and alternating loads. Reinforced concrete beams were made of concrete of C25/30 class and reinforced with two welded frames. As the working armature there was used the armature of A400 class with diameter of $12 \mathrm{~mm}$, a cross-reinforcement of A240 class with the diameter of $6 \mathrm{~mm}$. Reinforcement of beams is double symmetrical with two longitudinal rods from below and from above the beam section. The step of the cross rods at the supporting areas is $100 \mathrm{~mm}$, in spans $200 \mathrm{~mm}$. Continuous two-pass beams with identical spans of 1500 $\mathrm{mm}$ and cross-sectional dimensions of $100 \times 160 \mathrm{~mm}$ were tested with the help of a special power traverse using the hydraulic press PG-200. Loading of beams was carried out by four lumped forces, 
two forces in each span, which were applied according to the scheme shown in Fig. 1, which also shows the location of measuring devices.

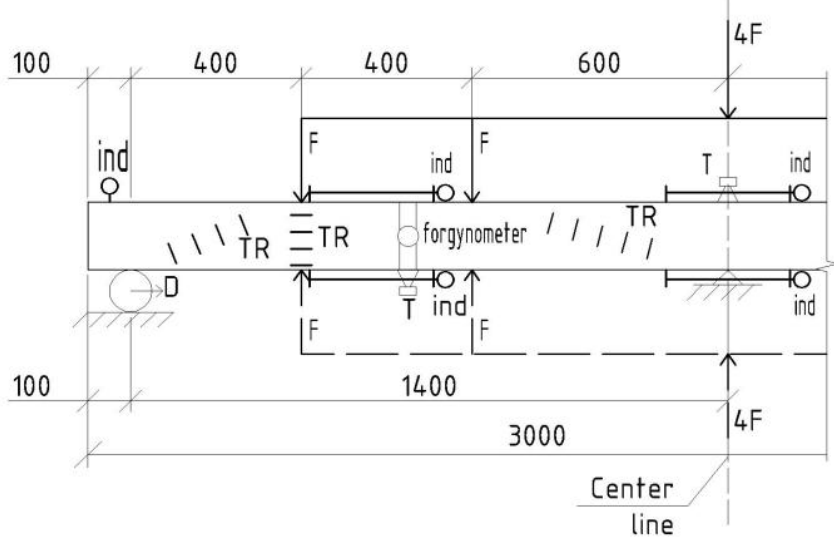

Fig. 1: Scheme of the application of forces and arrangement of measuring devices.

The scheme of testing beams in a special power plant using the press PG-200 is shown in Fig. 2

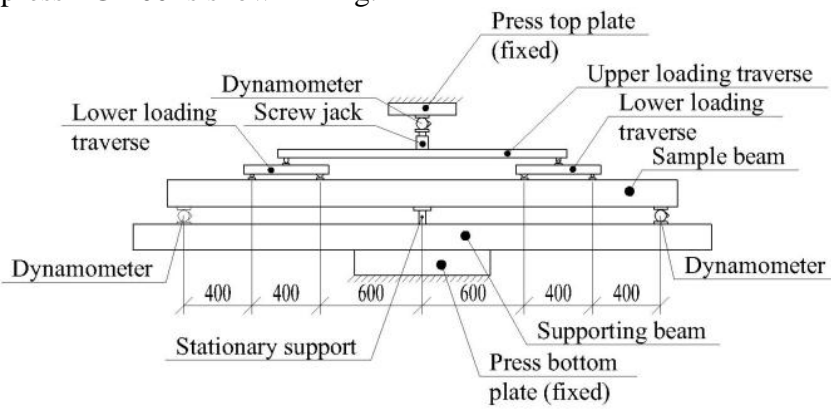

Fig. 2: Test scheme of two-pass beams

Testing samples was performed according to the following loading regimes: one-time static loading leading to fracture to determine loading levels; low-cyclic repeated loading with the upper level of 0,6 and lower $-0,3$; low-cyclic alternating loading with the level of 0.6. The number of cycles of low-cyclic loads taken is ten. After ten cycles of low-cyclic loads, the beams were carried to destruction. The schemes of loading modes of experimental samples are given in Table 1.

Table 1: Diagrams of beams loading modes

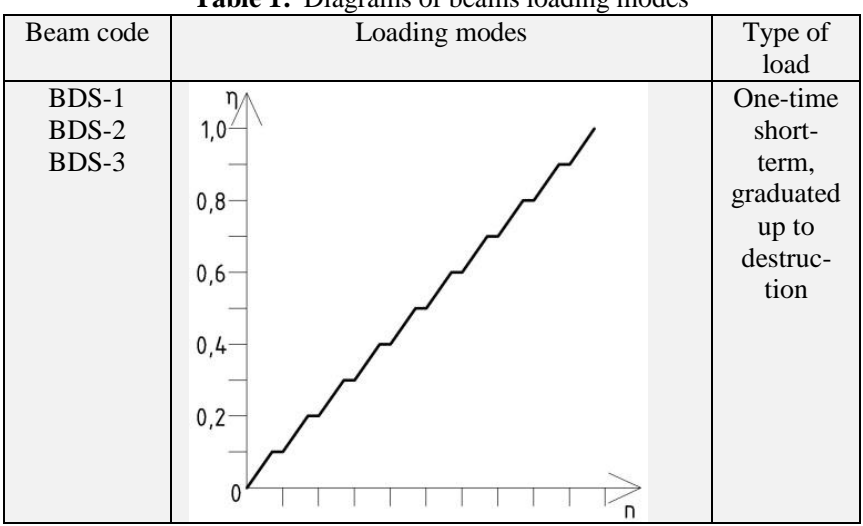

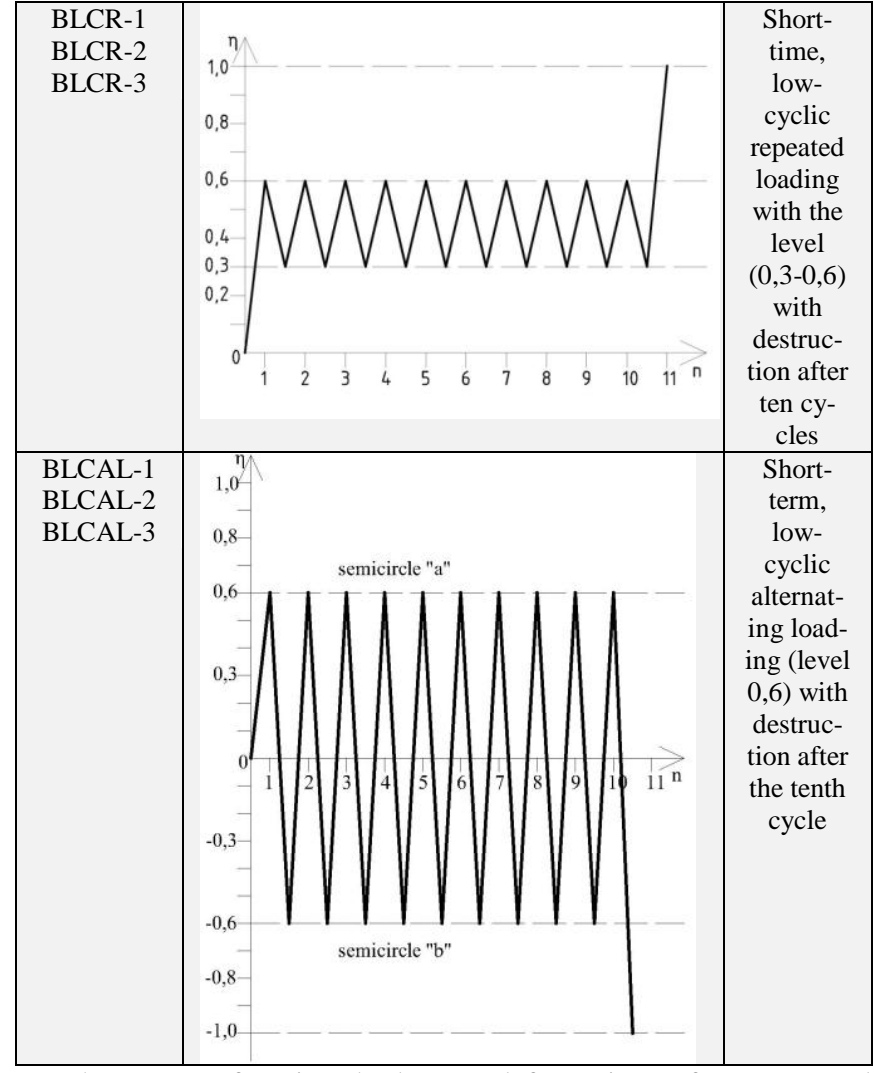

In the course of testing the beams, deformations of concrete and reinforcement, deflection of beams and the possible movement of extreme supports were measured. Concrete deformations were measured by clock-type indicators with the unit division of 0.001 $\mathrm{mm}$ based on $200 \mathrm{~mm}$ and strain gauges with the base of $50 \mathrm{~mm}$, glued in strands in spans where there were maximum positive bending moments under the first force from the extreme support and maximum negative moments under the central support, as well as in sloping sections from the support to the places of application of forces on the beam. The deformations of the armature were measured with the help of the Guggenberger strain gauge on the basis of $20 \mathrm{~mm}$ with the unit division of $0,001 \mathrm{~mm}$ and strain gauges based on $20 \mathrm{~mm}$, which were glued to the reinforcing bars. The deflection of the beams was measured by the deflection meters of type 6 of PAI LISI with the unit division of $0.01 \mathrm{~mm}$. The indicators of the clock type determined the movement of the outer supports. The appearance of cracks in the testing of beams was observed visually and with the help of a microscope MPB-3 with the unit division of $0.002 \mathrm{~mm}$. At each half-cycle of loading on the sides of the beams, the height of the normal hw and the length of inclined cracks lw were marked. Using this method of conducting experimental studies of beams with the designed equipment and the use of modern measuring instruments allowed to investigate the effects of the above mentioned loads on the actual stress-strain state of normal and inclined beam sections and changes in the testing process.

The mechanism of deformation, cracks formation and destruction of continuous beams is significantly different from the operation of single-pass reinforced concrete bending elements, even with unambiguous static loading (in the first half-cycle). With increasing loading, first appear normal cracks over the middle support in the zone of maximum momentum, then in spans between the concentrated forces and in the spans of the section of the stretched zone. Sloping cracks appeared during loading, which is on average 2.5 times higher than the load, at which normal cracks are formed. All this was fixed at the loading of beams on the 1st half-cycle with low-cyclic repeated and alternating loads. With further cyclic loading with each cycle, the stress-strain state of the beams changed. This was followed by the growth of deformations and cracks in the experimental samples. If we compare the stress-strain 
state of beams for the effects of low-cyclic repeated and lowcyclic alternating loads, then there is also a significant difference. The formation and development of cracks, which crossed practically all sections, were more characteristic in the appearance of values with increasing cycles. After changing the mark, the efforts of the microcracking were formed more intensively, interconnected and formed the main cracks. After the formation of the conditional plastic joint under the middle support (the stresses in the working armature have reached the yield strength) there appears redistribution of internal forces with a sharp increase in the bending moments in the spans with the maintenance of the maximum possible value of the bending moment over the middle support. The following conclusions can be made when carrying the beams to destruction due to the achieving the yield strength of the longitudinal armature and the analysis of the results of experimental studies.

\section{Conclusion}

The performed experimental researches of the operation of the two-pass reinforced concrete beams under the action of low-cyclic repeated and alternating loads give an opportunity to note that the above-mentioned loads significantly affect the stress-strain state and its change in the process of testing, as compared to unambiguous static loads. Under the action of low-cyclic repeated loads, the bearing capacity of the beams after ten cycles averaged $8 \%$, and for the effects of low-cyclic changes after ten cycles - by $16 \%$. Accordingly, deflections increased with low-cyclic repeated loads at the level of $\eta=0,6$ - by $12 \%$, and with low-cyclic alternatives by $40 \%$. The width of opening both normal and inclined cracks also increased. At the loading level of $\eta=0.6$, with a unambiguous static load, the width of normal cracks was $\mathrm{W}_{\mathrm{k}}=0.06 \mathrm{~mm}$, with a low-cyclic repetition after ten cycles $-\mathrm{W}_{\mathrm{k}}=0.14 \mathrm{~mm}$, and with a low-cyclic alternate after ten cycles $-\mathrm{W}_{\mathrm{k}}=0,6 \mathrm{~mm}$

The indicated changes of the stress-strain state must be taken into account when calculating statically-indefinite bending elements under the action of the above-mentioned loads by introducing the appropriate coefficients of working conditions. But for this purpose, it is necessary to accumulate the necessary data of experimental studies of such elements operation, which stipulates to continue further research on this problem.

\section{References}

[1] DBN B.2.6-98:2009 (2009). Buildings and structures construction Concrete and reinforced concrete construction. Fundamentals. Ministry of regional construction, Ukraine, $97 \mathrm{p}$.

[2] DSTU Б.B.2.6-156 (2011). Buildings and structures design. Concrete and reinforced concrete structures of high weight concrete Designing rules. Ministry of regional construction, Ukraine, 118p.

[3] European Committee for Standardization. (2003) pr EN 1992-11:2003. Eurocode 2, Design of Concrete Structures, Part 1: General Rules and Rules for Buildings, Brussels, Belgium, December, 230p.

[4] A.W. Beeby and R.S. Narayanan (2009) Designer's guide to EN 1992-1-1 and Eurocode 2: Design of concrete structures general rules and rules for buildings and structural fire design. Tomas Telford Ltd, London, 225p.

[5] V. S. Dorofeev (2010) Durability, crack resistance and deformability of continuous reinforced concrete beams. Odessa, 175p.

[6] V. S. Dorofeev (2007) Crack resistance and deformability of continuous beams, Theory and practice of construction, Journal of Lviv Polytechnic University, №600, Lviv, pp. 92-100.

[7] V. S. Dorofeev, V. M. Karpiuk, Ye. N. Krantovskaya (2006) Durability of sloping sections of continuous reinforced concrete beams, Journal of ODABA, Odessa, pp.85-94.

[8] V. S. Dorofeev, V. M. Karpiuk, Ye. N. Krantovskaya (2010) Peculiarities of stress and strain state of continuous reinforced concrete beams and calculation of sloping sections durability. Engineering structures: Proceedings of NDBIK, Issue 73. pp.151-163.
[9] V. S. Dorofeev, V. M. Karpiuk, Ye. N. Krantovskaya, A. M. Brednev (2010) Deformability of materials of continuous reinforced concrete beams. ODABA Journal, Odessa, pp. 246-254.

[10] V. S. Dorofeev, V. M. Karpiuk, Ye. N. Krantovskaya (2010) Calculation of bending of continuous reinforced concrete beams. Resource saving materials, structures and buildings. Proceedings of NUWEE, Issue 20, Rivne, pp. 193-204.

[11] V. S. Dorofeev, V. M. Karpiuk, Ye. N. Krantovskaya, V. M. Karpiuk (2009) Calculation of durability of sloping sections of continuous reinforced concrete beams. Resource saving materials, structures and buildings. Proceedings of NUWEE, Issue 19, Rivne, pp. 138-139.

[12] V. S. Dorofeev, V. M. Karpiuk, Ye. N. Krantovskaya (2011) Strain of longitudinal armature and redistribution of bending moments in continuous reinforced concrete beams. Resource saving materials, structures and buildings. Proceedings of NUWEE, Issue 21, Rivne, pp.215-223.

[13] G. H. Masiuk, V. Ye. Babych (2002) Experimental studies of efforts redistribution in two-pass continuous reinforced concrete beams under repeated loading. Journal of UAWM, Rivne, Issue 4(17), pp. 165-173.

[14] V. Ye. Babych (1999) stress and strain state of continuous reinforced concrete beams considering the diagram of concrete deformation. Scientific journal of construction, Kharkiv, Issue 7 pp.101 107.

[15] G. H. Masiuk, V. Ye. Babych (2004) calculation of durability of normal sections of continuous reinforced concrete beams under repeated loading on the basis of deformation model. Engineering structures, Kyiv, pp.659-664.

[16] V. Ye. Babych (2002) Peculiarities of operation of continuous reinforced concrete beams, reinforced with steel without yield strength under repeated loading Resource saving materials, structures and buildings. Proceedings of NUWEE, Issue 8, Rivne, pp. 47-55.

[17] V. V. Savytskiy (2003) Experimental studies of bends and width of cracks in precast monolithic continuous reinforced concrete beams under repeated loading Resource saving materials, structures and buildings. Proceedings of NUWEE, Issue 9, Rivne, pp. 303-310. 